Int. J. Dev. Biol. 58: 335-341 (2014)

doi: $10.1387 / \mathrm{ijdb} .130289 \mathrm{yk}$

\title{
Palatal adhesion is dependent on Src family kinases and P38MAPK
}

\author{
YUKIKO KITASE and CHARLES F. SHULER* \\ Oral Biological and Medical Sciences, Faculty of Dentistry, University of British Columbia, Vancouver BC, Canada
}

\begin{abstract}
During secondary palate development, palatal shelves adhere to each other in the midline to form a midline epithelial seam leading to palatal closure. Cell-cell and cell-extracellular matrix adhesions, which are mediated by cell adhesion receptors, E-cadherin and integrins, are implicated in the process of adhesion of the palatal shelves. Src family kinases (SFK) function downstream of both receptors. In this study, we focused on the role of SFK in the process of palatal adhesion. During palatal adhesion, the expression of SFK mRNA, as well as localization and quantitation of the protein in the activated form, were examined by real-time qPCR and immunofluorescence. Palatal organ cultures were performed to identify the effect of pharmacological inhibition of SFK on palatal adhesion. Activated SFKs were found to be co-localized with adhesion receptors, E-cadherin and integrins in the palatal medial edge epithelium. Src, Fyn andYes subfamily members were expressed in the palatal tissue. The expression of SFK mRNA and the quantity of the activated form of the protein were upregulated during palatal adhesion. An SFK inhibitor, PP2, blocked palatal adhesion, but another SFK inhibitor, SU6656 was not inhibitory. However, the combination of SU6656 and either of the p38MAPK inhibitors, SB203580 or BIRB0796, showed similar inhibitory effects on palatal adhesion compared to PP2 alone. The p38MAPK inhibitors alone did not alter palatal adhesion. Real-time qPCR revealed that p38MAPK $\alpha$ and $\delta$ were elevated during palatal adhesion. This study indicates that palatal cell adhesion is dependent on signaling from integrin receptors and E-cadherin through SFK and p38MAPK.
\end{abstract}

KEY WORDS: Src family kinases (SFK), p38MAPK, palatal adhesion

\section{Introduction}

Secondary palate development requires a multi-step sequence; initiation, vertical outgrowth, reorientation, adhesion and fusion stages (Bush and Jiang, 2012). Disturbance in any of these stages can result in cleft palate. During the adhesion stage, the palatal shelves approach each other, contact in the midline allowing the opposing medial edge epithelia (MEE) to adhere, and eventually form the midline epithelial seam (MES) to completely bridge the gap between the palatal shelves (Bush and Jiang, 2012). Adhesion and the next stage, fusion occur in a narrow window of time. Many studies have been focused on the molecular mechanisms of MEE cell fate specification during the palatal fusion stage (Bush and Jiang, 2012), but there has been little research performed to understand the molecular mechanisms regulating the process of palatal adhesion.

During the adhesion stage, both cell-cell and cell-extracellular matrix (ECM) adhesions have been shown to effect intracellular signaling pathways that promote the adhesion of palatal shelves (Huveneers and Danen, 2009, van Roy and Berx, 2008). E-cadherin is the major cadherin molecule expressed by epithelial cells including MEE (Sun et al., 1998). E-cadherin is primarily responsible for initiating MEE cell adhesion and forming the calcium dependent adherens junctions (van Roy and Berx, 2008). An E-cadherin mutation lacking the extracellular domain required for cell-cell adhesion has been linked to the appearance of cleft lip and palate (Frebourg et al., 2006). Integrins regulate cell-ECM adhesions (Huveneers and Danen, 2009). Deletion of integrin $\alpha \mathrm{V}$ resulted in the lack of $\alpha \mathrm{V} \beta 1, \alpha \mathrm{V} \beta 3, \alpha \mathrm{V} \beta 5, \alpha \mathrm{V} \beta 6$, and $\alpha \mathrm{V} \beta 8$ integrins and was linked to a cleft palate phenotype (Munger and Sheppard, 2011). Anti-integrin $\alpha 5$ blocking antibody caused significant reduction in the adhesion of palatal shelves up to $70 \%$ (Martinez-Sanz et al., 2008). Enzymatic digestion of chondroitin sulphate proteoglycan

Abbreviations used in this paper: MEE, medial edge epithelium; MES, midline epithelial seam; SFK, Src family kinase.

\footnotetext{
*Address correspondence to: Charles F. Shuler. 2194 Health Sciences Mall, Vancouver, BC V6T 1Z3, Canada. Tel: 604 822-5773. Fax: 604 822-4532.

E-mail: cshuler@dentistry.ubc.ca
} 
which interacts with integrins to mediate signals led to the inhibition of palatal adhesion (Gato et al., 2002). These studies indicate the crucial roles of both adhesion receptors: E-cadherin and integrins, in the process of palatal adhesion. The downstream molecular mechanisms regulating palatal MEE adhesion however have not been fully elucidated.

Non-receptor tyrosine kinases, Src family kinases (SFK) are well known to accumulate at both the cell-cell adherence junctions and cell-extracellular matrix adhesions (Huveneers and Danen, 2009, McLachlan et al., 2007). SFK consist of nine members including Src, Fyn, Yes and Fgr (Thomas and Brugge, 1997). Src, Fyn and Yes are expressed ubiquitously in all cell types but other family members including Fgr are generally expressed in hematopoietic cell lineages (Thomas and Brugge, 1997). The myristoylation signal in the Src homology (SH) 4 domain targets SFK to the plasma membrane, where SFK regulate focal adhesions and cell-cell adhesions downstream of integrins and E-cadherin (Patwardhan and Resh, 2010). The interaction of integrin with ECM causes SFK activation by direct interaction with the SH3 domain through the integrin $\beta$ cytoplasmic tail, which results in phosphorylation of Tyr-418 in the kinase domain (Arias-Salgado et al., 2003). Src and Fyn selectively bind to integrin $\beta 3$ while Yes can bind integrin $\beta 1$, $\beta 2$ and $\beta 3$ (Arias-Salgado et al., 2003). E-cadherin also activates SFK at cell-cell contacts and positively supports cadherin-mediated hypothesized that SFK function associated with E-cadherin- and integrin-mediated adhesion of the MEE may play an important role in palatal adhesion.

p38MAPK has four isoforms, p38MAPK $\alpha, \beta, \gamma$ and $\delta$ that mediate signals downstream of integrins via activation of Rho GTPases/ MAPK kinases and FAK/SFK (Aikawa et al., 2002, Han et al., 2002). Although p38 MAPK has been shown to regulate the process of palatal fusion, the role of p38MAPK has not been examined in the palatal MEE adhesion stage (Xu et al., 2008).

The present studies focus on the MEE adhesion stage of palatal development and the role of SFK and p38MAPK during that stage. Co-localizations of active SFK with the adhesion receptors in MEE led us to examine the expression pattern of SFK mRNA and the activated kinases during palatal adhesion. Organ cultures of fetal palatal shelves were used to evaluate the role of SFK and p38MAPK through the use of pharmacologic inhibition of kinase activity.

\section{Results}

\section{The expression pattern of SFK during palatal adhesion}

To investigate the involvement of SFK in MEE during the process of palatal adhesion, we examined co-localization of activated SFK (red) with the adhesion receptors (green), E-cadherin and integrin $\beta 1$ and $\beta 3$ by immunofluorescence using 24 horgan cultured palatal shelves. Cell-cell contacts between opposing adherent palatal shelves show yellow color (arrows in each merged image of Fig. 1A). This indicates co-localization of activated SFK and E-cadherin, integrin $\beta 1$ or $\beta 3$ at cell-cell contacts between opposing adherent palatal shelves. At the basement membrane, merged images of phospho-SFK with integrins showed yellow color but only red color adhesion (Calautti et al., 1998, Tsukita et al., 1991). We therefore

A
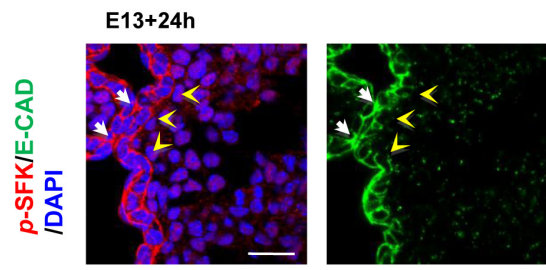

Merged images
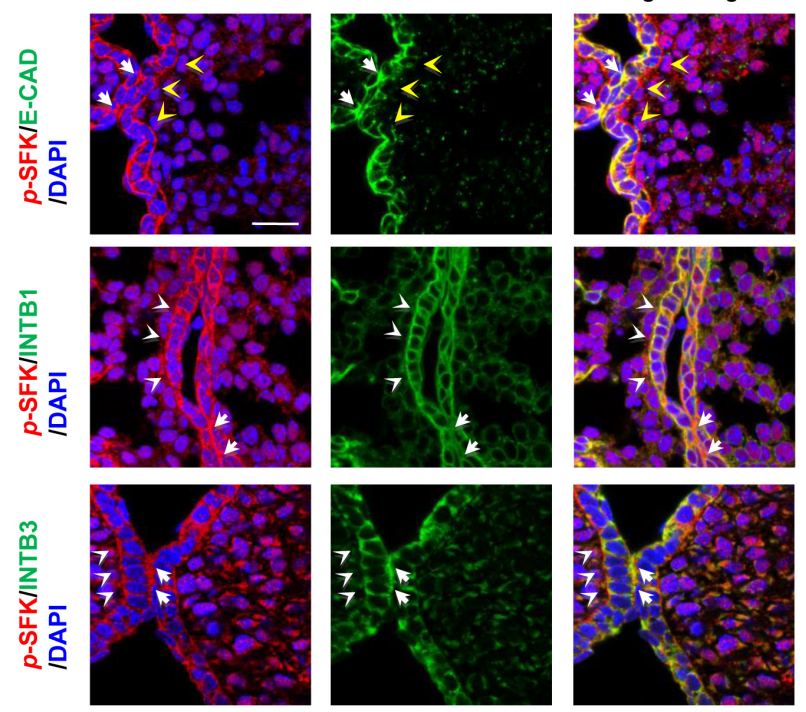

B
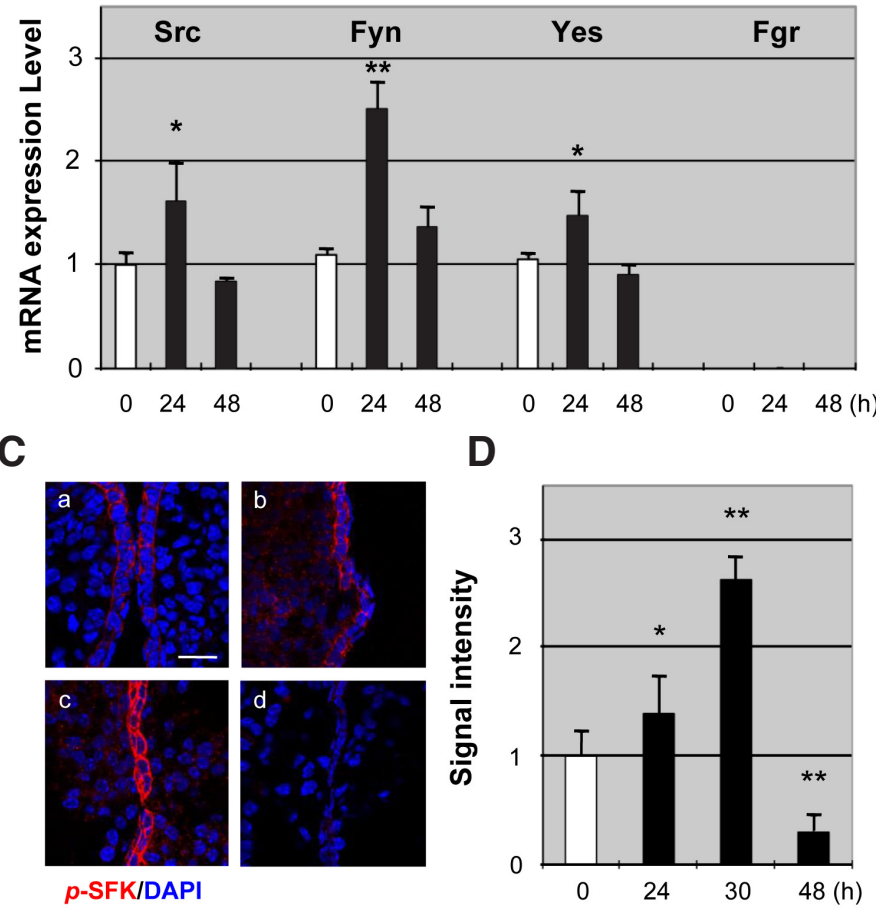

Fig. 1.The expression pattern of SFK during palatal adhesion. (A) Fluorescentimages of phospho-SFK (red), E-cadherin (green), integrin $\beta 1$ (green), integrin $\beta 3$ (green) and DAPI (blue). Representative single optical sections were taken at $24 \mathrm{~h}$ of palatal organ cultures dissected from E13.0 fetuses. Arrows: co-localization with phospho-SFK and E-cadherin or integrins at cell-cell contacts in MEE between opposing adherent palatal shelves. Arrowheads: co-localization with phospho-SFK and integrins (white arrows), but not E-cadherin (yellow arrows) at basement membrane. Scale bar, 20 um. (B) Quantitative real-time PCR analysis of gene expression encoding Src subfamily members; Src, Fyn, Yes and Fgr in the mid-region of palatal tissue at $0,24 \mathrm{~h}$ and $48 \mathrm{~h}$ of palatal organ culture. GAPDH was used as reference for normalization. mRNA expression level was expressed as fold induction based on that of Src at Oh. ${ }^{*} \mathrm{p}<0.05$ and ${ }^{*} \mathrm{p}<0.01$ compared to Oh. (C) Fluorescent images of phospho-SFK (red) and DAPI (blue). Representative single optical sections were taken from palatal tissue at Oh (a), $24 \mathrm{~h} \mathrm{(b),} \mathrm{30h} \mathrm{(c)} \mathrm{and} 48 \mathrm{~h}$ (d) of palatal organ cultures. (D) Signal intensity of phospho-SFK at each time point, which was expressed as fold induction based on the intensity at Oh. Scale bar, $20 \mu \mathrm{m}$. ${ }^{*} \mathrm{p}<0.05$ and ${ }^{*} \mathrm{p}<0.01 \mathrm{compared}$ to $0 \mathrm{~h}$. 
A

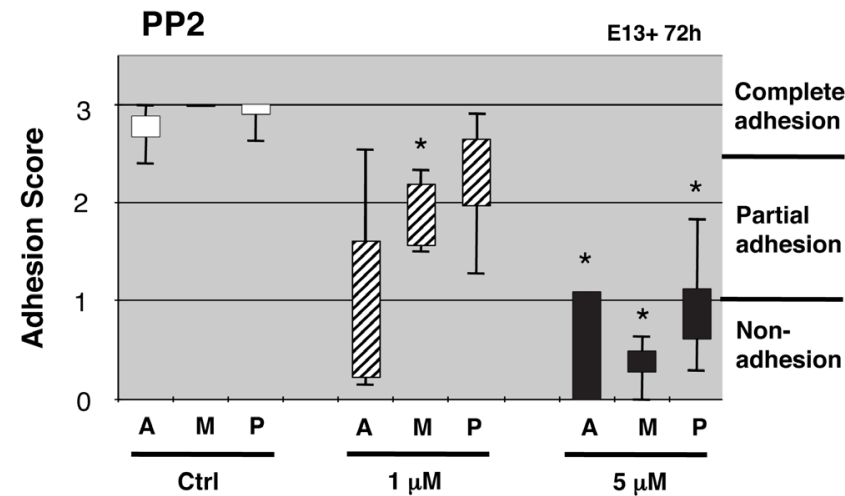

C

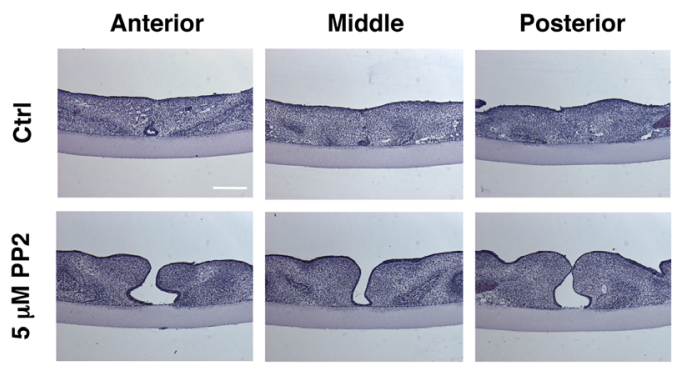

B SU6656
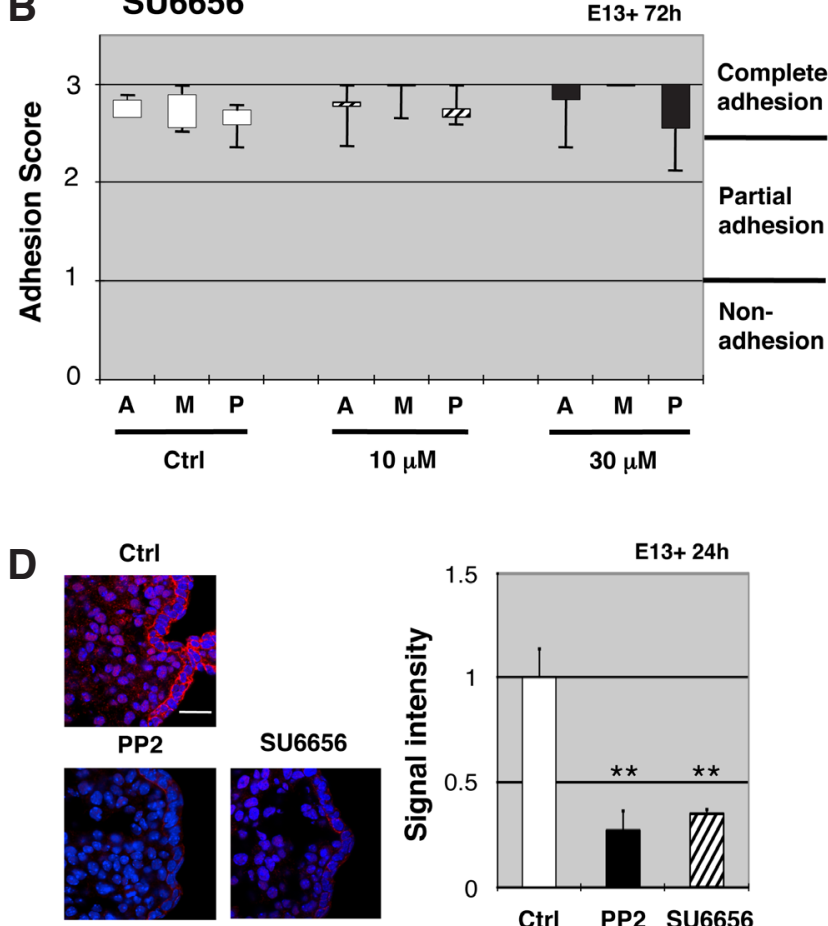

p-SFK/DAPI
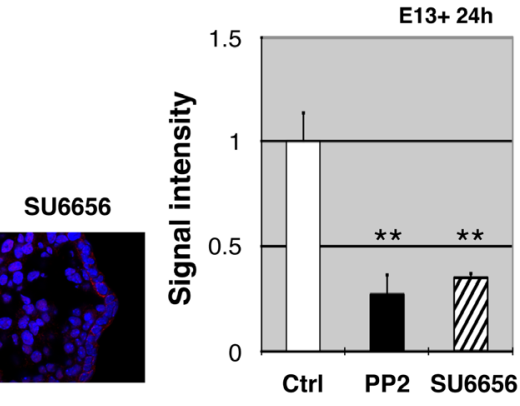

Fig. 2. SFK inhibitor, PP2 blocked palatal adhesion, but not another inhibitor, SU6656. (A) Adhesion scores were obtained from the three different regions; anterior $(A)$, middle $(M)$ and posterior $(P)$ of $72 \mathrm{~h}$ organ cultured palatal tissue treated with or without 1 or $5 \mu M P P 2$. ${ }^{*} \mathrm{p}<0.05$ compared to control in each region. Hematoxylin staining. Representative sections from $72 \mathrm{~h}$ organ cultured palatal tissue were shown for control and $5 \mu \mathrm{M} P P 2$. Scale bar, $200 \mu \mathrm{m}$. (B) Adhesion scores were obtained from the three different regions of $72 \mathrm{~h}$ organ cultured palatal tissue treated with or without 10 or $30 \mu \mathrm{M}$ SU6656. * $\mathrm{p}<0.05$ compared to control in each region. (C) Fluorescent images of phospho-SFK (red) and DAPI (blue). Representative single optical sections were taken from palatal tissue at $24 \mathrm{~h}$ of palatal organ culture. (D) Signal intensity of phospho-SFK was expressed as fold induction based on the intensity in control. Scale bar, $20 \mu \mathrm{m}$. ${ }^{*} \mathrm{p}<0.01$ compared to control.

was observed in the merged image with E-cadherin. This indicates activated SFK are co-localized with integrins (white arrowheads), but not E-cadherin (yellow arrowheads) at the basement membrane. This result led us to investigate the expression pattern of SFK mRNA and the activated kinase protein during palatal adhesion by real-time QPCR and immunofluorescence. In Fig. 1B the mRNA expression levels of Src related subfamily members; Src, Fyn, Yes and Fgr are presented and Src, Fyn and Yes were the only SFK detected. All three members had similar expression patterns with upregulation at $24 \mathrm{~h}$ of palatal organ cultures and a return to the baseline by $48 \mathrm{~h}$, only Fyn exhibited more than a 2 -fold increase. Immunofluorescence analysis of the activated kinase demonstrated that the phosphorylation level of SFK started to increase at $24 \mathrm{~h}$ of organ cultures (before adhesion) (Fig. 1C). The maximum level of the phosphorylated kinase, a 2.5-fold increase, was detected at $30 \mathrm{~h}$ (after adhesion). The activity was reduced by about one-third at $48 \mathrm{~h}$ as the adhesion process was completed.

\section{The SFK inhibitor, PP2, blocked palatal adhesion}

We next performed pharmacological inhibition of SFK in palatal shelf organ culture to examine the role of SFK during palatal adhesion and adhesion scores were obtained at 72h. Fig. 2A showed that $5 \mu \mathrm{M}$ PP2 blocked palatal adhesion in all the three regions; anterior, middle and posterior. After $72 \mathrm{~h}$ of organ culture, palatal tissue was completely fused in the controls while midline gaps between opposing palatal shelves were observed in the samples treated with PP2. Adhesion score results indicate a more profound inhibitory effect of PP2 in the anterior and middle regions when compared to the posterior region. Organ cultures with different treatment durations of PP2 revealed that treatment with PP2 was required for the entire culture period to exhibit the maximum inhibitory effect (data not shown). Another SFK inhibitor, SU6656, however, did not inhibit the palatal adhesion in all three regions, even at $30 \mu \mathrm{M}$ (Fig. 2B). Immunofluorescence confirmed that both PP2 and SU6656 inhibit approximately $70 \%$ of signal intensity of phospho-SFK at $24 \mathrm{~h}$ of palatal organ culture (Fig. $2 \mathrm{C}$ ). This result indicated that multiple types of kinases were required to complete palatal MEE adhesion.

\section{Combination of SU6656 and p38MAPK inhibitors can inhibit palatal adhesion}

A previous study showed a critical difference in the specificity of both SFK inhibitors, PP2 and SU6656 (Bain et al., 2007). PP2 inhibited kinase activities including p38MAPK $\alpha$ and $\beta$, casein kinase 1 (CK1), c-SRC tyrosine kinase (CSK), receptor interacting protein-2 (RIP2) and cyclin G-associated kinase (GAK) in addition to SFK, while SU6656 had a more restricted range of kinase inhibition (Bain et al., 2007). To investigate the involvement of p38MAPK in the process of palatal adhesion, we decided to examine the effect of combinations of the SFK inhibitor SU6656 and p38MAPK inhibitors on palatal adhesion. A combination of SU6656 and SB203580, which inhibits CK1, RIP2 and GAK as well as p38MAPK $\alpha$ and $\beta$ 
A

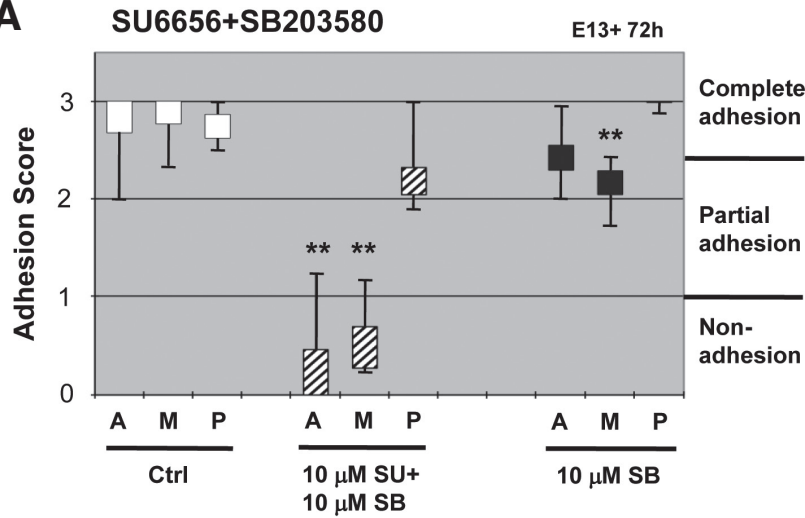

B
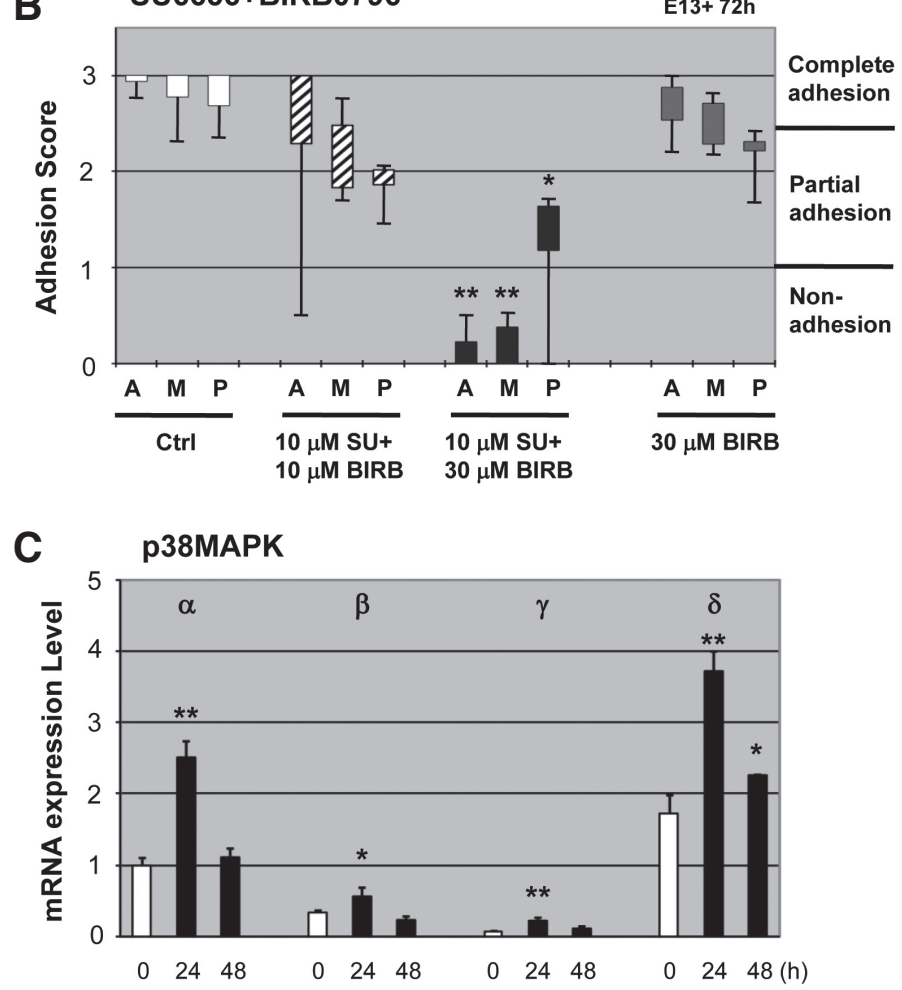

was tested. SU6656 combined with SB203580 inhibited palatal adhesion, especially the anterior and middle regions (Fig. 3A). The second combination of SU6656 and BIRB0796, which inhibits all the p38MAPK isoforms but not the other kinase had a more substantial effect on palatal adhesion compared to the first combination (Fig.3 B). Single use of either SB203580 or BIRB0796 however had no significant effect on palatal adhesion (Fig. $3 \mathrm{~A}$ and B). Analysis of p38MAPK isoforms by real-time QPCR indicated that p38MAPK $\alpha$ and $\delta$ were the most abundant in the palatal tissue (Fig. $3 \mathrm{C}$ ).

\section{Discussion}

In this study, we have shown functional redundancy of SFK and p38MAPK to facilitate the process of palatal MEE adhesion in palatal organ culture. Pharmacological concurrent inhibition of both kinases resulted in a failure of palatal MEE adhesion.

E-cadherin and integrins play important roles in the process of
Fig. 3. Combination of SU6656 and p38MAPK inhibitors can inhibit palatal adhesion. (A) Adhesion scores were obtained from the three regions; anterior $(A)$, middle $(M)$ and posterior $(P)$ of $72 \mathrm{~h}$ organ culture palatal tissue treated with combination of $10 \mu \mathrm{M}$ SU6656 (SU) and $10 \mu \mathrm{M}$ SB203580 (SB) or single use of $10 \mu \mathrm{M}$ SB203580. ${ }^{*} \mathrm{p}<0.01$ compared to control in each region. (B) Adhesion scores were obtained from the three regions of $72 \mathrm{~h}$ organ culture palatal tissue treated with combination of $10 \mu M$ SU6656 (SU) and 10 or $30 \mu M$ BIRB0796 (BIRB) or single use of $30 \mu M$ BIRB0796. ${ }^{*} \mathrm{p}<0.05$ and ${ }^{*} \mathrm{p}<0.01$ compared to control in each region. (C) Quantitative real-time PCR analysis of gene expression encoding $\mathrm{p} 38 \mathrm{MAPK}$ isoforms; $\alpha, \beta, \gamma, \delta$ in the mid-region of palatal tissue at $0,24 \mathrm{~h}$ and $48 \mathrm{~h}$ of palatal organ culture from tissue originally dissected from E13.0 fetuses. GAPDH was used as reference for normalization. mRNA expression level was expressed as fold induction based on that of p38MAPK $\alpha$ at 0 h. ${ }^{*} \mathrm{p}<0.05$ and ${ }^{*} \mathrm{p}<0.01$ compared to $0 h$.

palatal adhesion (Frebourg et al., 2006, Martinez-Sanz etal., 2008, Munger and Sheppard, 2011). To investigate the involvement of SFK in E-cadherin- and integrin-mediated palatal adhesion, double immunofluorescence labeling was performed. We identified colocalization of active SFK with E-cadherin and integrins at cell-cell contacts where palatal shelves are adherent, which indicated a potential role of SFK function during the stage of palatal adhesion. Real time QPCR revealed the expression pattern of SFK during palatal adhesion and identified Fyn as the most up-regulated gene among the three ubiquitously expressed SFK family members. Fyn has been implicated in positively regulating E-cadherin mediated keratinocyte cell-cell adhesion in vitro (Calautti et al., 1998, Calautti et al., 2002). In vivo, however, a deletion of both Fyn and Src were required to cause impaired keratinocyte cell adhesion (Calautti et al., 1998). Fyn appears to be the most relevant among the three SFK, but there may be functional redundancy in the regulation of the palatal adhesion. Each different member may be differently activated in the course of organ culture during $48 \mathrm{~h}$, which may result in the continuous expression of the phosphorylated form. The sequence of SFK activation provided evidence of a moderate level of activation occurring even before the adhesion of the opposing MEE, which could be the result of the initial changes of the cell adhesion molecules to prepare the MEE for adhesion. The maximum activation of SFK was not observed until after adhesion of the opposing MEE. In prior publications there is a paradoxical role of SFK in the establishment of cell adhesions. Cell adhesion requires active SFK but hyperactivation of SFK results in disruption of the adhesions as observed in oncogene-transformed or mitogenically stimulated cells (McLachlan et al., 2007). Therefore, differential intensity of phospho-SFK in MEE before and after palatal adhesion may suggest the different roles of SFK in the different stages. Positive effects during the palatal adhesion and negative effects during palatal fusion where E-cadherin mediated cell-cell adhesion is disrupted in MEE as the midline seam breaks down and the mesenchyme becomes continuous between both palatal shelves.

We performed palatal organ cultures with PP2, which is a commonly used inhibitor of SFK. PP2 blocked palatal adhesion in all three midline regions, suggesting that SFK positively regulate the process of palatal adhesion. However, we surprisingly found that another SFK inhibitor, SU6656, had very limited effect on palatal adhesion despite it can inhibit the phosphorylation of SFK as well as PP2. We thought this was due to the different non-specific effects of both PP2 and SU6656 on other kinases (See Fig. 4A). Kinases 
A

$$
\begin{aligned}
& \text { CK1, RIP2 } \\
& \text { and GAK }
\end{aligned}
$$
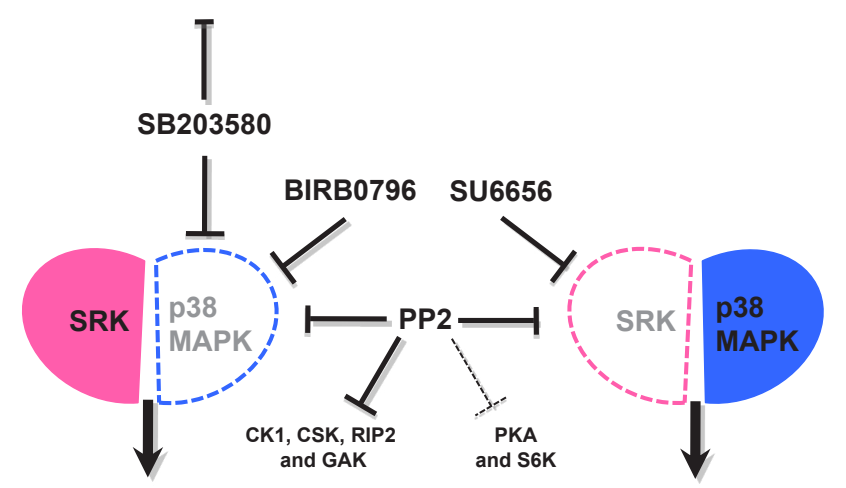

Palatal Adhesion

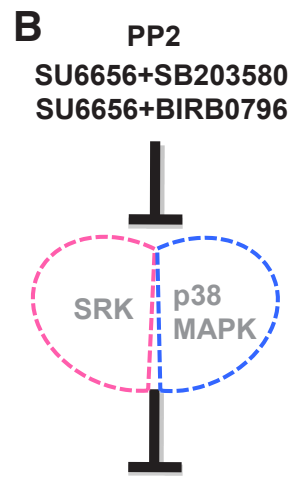

Palatal Adhesion

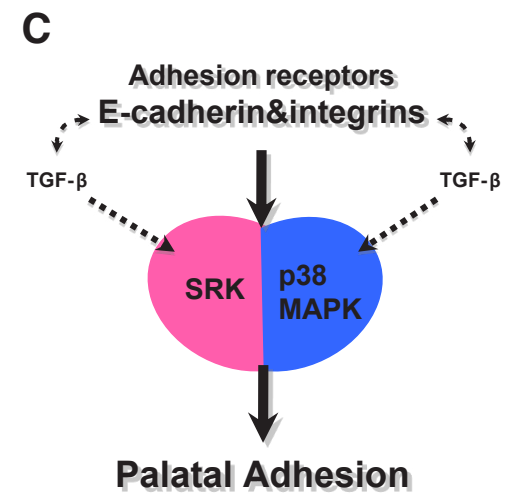

Fig. 4. A diagram of signaling pathways regulating palatal adhesion and kinases targeted by the inhibitors used in this study. (A) Single use of SU6656 and p38MAPK inhibitors did not inhibit palatal adhesion. Kinases inhibited more than $50 \%$ by PP2 but not SU6656 are p38MAPK, CK1, CSK, RIP2 and GAK. SB203580 inhibits CK1, RIP2 and GAK more than $50 \%$, but not BIRB0796. PP2 also showed additional moderate inhibition against PKA and S6K. (B) Concurrent inhibition of both SFK and p38MAPK caused a failure of palatal adhesion. (C) The process of palatal adhesion mediated by E-cadherin and integrins is dependent on SFK and p38MAPK.

inhibited more than $50 \%$ by PP2 but not SU6656 are p38MAPK, CK1, CSK, RIP2 and GAK (Bain et al., 2007). Since p38MAPK is downstream of integrins (Aikawa et al., 2002, Han et al., 2002), we speculated that p38MAPK were also involved in the process of palatal adhesion. We therefore decided to perform palatal organ cultures with combinations of inhibitors using SU6656 in combination with the p38MAPK inhibitors, either SB203580 or BIRB0796. SB203580 inhibits CK1, RIP2 and GAK more than $50 \%$, but not BIRB0796 (Fig. 4A). The different specificity between them allowed us to exclude the requirement of CK1, RIP2 and GAK in adhesion. Both p38MAPK inhibitors as well as SU6656 do not inhibit CSK while PP2 does (Bain et al., 2007, Fig. 4A), which indicates that CSK is not required for the process of palatal adhesion. Single use of either SU6656 or p38MAPK inhibitors did not inhibit palatal adhesion, but concurrent inhibition of both SFK and p38MAPK caused a failure of palatal adhesion (Fig. 4A and B). Thus, SFK and P38MAPK exhibit redundancy in facilitating the required phosphorylation events necessary for palatal adhesion (Fig. 4C).
PP2 and combinations of SU6656 and p38MAPK inhibitors showed different effects on adhesion in the posterior region. All three regions of the palatal midline in PP2 treated palate were classified into the non-adhesion group (Median: 0, 0.3 and 1.0 in anterior, middle and posterior regions respectively). However, the posterior region of palates treated with both SU6656 and p38MAPK inhibitors was classified into the partial adhesion group (Median: 1.5 and 2.1 in SU6656/30 $\mu \mathrm{M}$ BIRB0796 and SU6656/SB203580 respectively). Unlike the combination of SU6656 and p38MAPK inhibitors, PP2 showed additional moderate inhibition against PKA and S6K (Bain et al., 2007, Fig. 4A). Both are downstream of integrin signaling (Lim et al., 2008, Malik and Parsons, 1996). PKA also regulate integrin mediated cell adhesion (Whittard and Akiyama, 2001). Therefore these kinases may play roles in regional regulation of palatal development along the anterior-posterior axis. We cannot however exclude the involvement of other kinases sensitive to PP2 and specific for the posterior region leading to the distinct regional response to the inhibitors.

Based on the results of organ cultures and real time QPCR, p38MAPK $\alpha$ and $\delta$ were the main isoforms functioning cooperatively with SFK family member, Src, Fyn and Yes during palatal adhesion.

The present study indicates the functional redundancy of SFK and p38MAPK in facilitating the process of palatal adhesion mediated by E-cadherin and integrin (Fig. 4C). TGF- $\beta$ plays an important role in the palatal adhesion (Kaartinen et al., 1995). It activates SFK and p38MAPKs (Pechkovsky et al., 2008, Wendt and Schiemann, 2009) and crosstalk between TGF- $\beta$ and the adhesion receptors were also observed in other systems (Galliher and Schiemann, 2006, Galliher-Beckley and Schiemann, 2008, Kim et al., 2009). It would therefore be interesting to examine the relationship between TGF- $\beta$, the adhesion receptors and the kinases during palatal adhesion. Further studies will be required to conclusively demonstrate which SFK family members and p38MAPK isoforms are involved in the process and identify the upstream and downstream signaling molecules regulating the adhesion stage. The possible involvement of other integrin-related downstream signaling molecules such as FAK and the Rho family of GTPases in the adhesion process also warrants future investigation.

\section{Materials and Methods}

\section{Palate organ culture}

All animal procedures were performed in compliance with the regulations and guidelines of the Animal Care Committee of The University of British Columbia. Timed-pregnant C57BL6 mice were used in these studies. The palatal shelves were dissected from E13.0 fetal murine heads under sterile conditions and placed in pairs on Millipore filters with correct anteriorposterior orientation and with their medial edges in contact. The palatal shelves were cultured in BGJb medium at $37^{\circ} \mathrm{C}$ in $5 \% \mathrm{CO}_{2}$ for up to $\mathrm{E} 13$ $+72 \mathrm{~h}$. Experimental groups were treated with pharmacological inhibitors dissolved in DMSO (1 or $5 \mu \mathrm{M}$ PP2, $10 \mu \mathrm{M}$ SU6656, $10 \mu \mathrm{M}$ SB203580, 10 or $30 \mu \mathrm{M}$ BIRB0796) whereas littermate control groups were treated only with the DMSO solvent. Treatment with the inhibitors or the solvent occurred throughout the entire organ culture period. The culture media was changed every $24 \mathrm{~h}$.

\section{Histology}

Cultured palatal shelves were collected at the indicated time points and fixed in 4\% PFA/PBS. After rinsing with PBS, the tissues were processed for paraffin embedding. Light microscopic analysis after H\&E staining was performed to evaluate adhesion score. One of every 10 sections $(7 \mu \mathrm{m}$ 
thickness) was examined. Adhesion scores (0-3) were assigned to the coronal sections from three regions: anterior, middle and posterior parts. 0: no adhesions, 1 : less than one-half, 2: equal to or more than one-half and 3: closure. Median (M) of adhesion score was utilized to classify into three groups, non-adhesion $(0 \leq M \leq 1)$, partial adhesion $(1<M<2.5)$ and complete adhesion $(2.5 \leq M \leq 3)$. Five palates for each group from two different litters were analyzed. Post hoc power analysis by G*Power 3.1 revealed statistical power of at least 0.7 (range $0.7 \sim 1$ ) in each adhesion score experiment.

\section{Immunofluorescence}

Frozen sections or paraffin sections with EDTA antigen retrieval were blocked with $3 \%$ BSA/PBS for $30 \mathrm{~min}$ at room temperature to reduce background staining and incubated with the primary antibody against phospho-SFK (EMD Millipore, 1:50) and phospho-p38MAPK (Cell Signaling Technology, 1:100), E-cadherin (BD Bosciences, 1:100), integrin $\beta 1$ (R\&D systems, 1:100) and integrin $\beta 3$ (LifeSpan BioSciences, 1:100) at room temperature for $2 \mathrm{~h}$, followed by three rinses in PBS. Fluorescence-labeled secondary antibodies (Alexa Fluor 488 and $568 \mathrm{lgG}(\mathrm{H}+\mathrm{L})$, Invitrogen, $1: 100)$ were added for $1 \mathrm{~h}$ at room temperature. After washing with PBS three times, coverslips were mounted with mounting medium including DAPI. To confirm the specificity of antibodies, additional slides were incubated without the primary antibodies. No fluorescence was found in these sections. All sections were examined by using a Nikon Laser Scanning Confocal microscope (C1) and single optical images were obtained. Quantification analysis of immunofluorescence intensity was performed by using NIH ImageJ. We measured fluorescence intensity by defining the MEE remaining area manually, and calculated the mean pixel intensity per unit area of MEE remaining.

\section{Quantitative Real Time PCR}

For each time point, mid-regions of the midline from 2 pairs of palatal shelves were pooled, and 3 5 independent pools were analyzed. Total RNA was extracted with the use of RNeasy plus mini kit (Qiagen) and reverse transcribed with iScript cDNA synthesis kit (Qiagen) according to the manufacturer's guidelines. SYBR-Green based real-time PCR was performed using SsoFast EvaGreen Supermix (Bio-Rad). Primers used in this study were obtained from PrimerBank (Spandidos et al., 2010). Src (forward: GAA CCC GAG AGG GAC CTT C, reverse: GAG GCA GTA GGC ACC TTT TGT), Fyn (forward: ACC TCC ATC CCG AAC TAC AAC, reverse: CGC CACAAACAG TGT CAC TC), Yes (forward: AGT CCA GCC ATA AAA TAC ACA CC, reverse: TGA TGC TCC CTT TGT GGA AGA), Fgr (forward: CGG CTG AAG AAC GCT ATT ACC, reverse: GGG CGA CGA ATA TGG TCA CTC) p38MAPK $\alpha$ (forward: TGA CCC TTA TGA CCA GTC CTT T, reverse; GTC AGG CTC TTC CAC TCA TCT AT), P38MAPK $\beta$ (forward: ATG TAG CGG TGAACG AGG AC, reverse: CCA CAT ATC CGG TCA TCT CC) p38MAPK $\gamma$ (forward: GAG ACT TGA AGC CTG GCA AC, reverse; CCG GGT TAC CAC ATA TCC TG), p38MAPK (forward: CGC CAC ACA GAC ACT GAG AT, reverse; ATG ATG CAA CCAACA GAC CA), GAPDH (forward: AGG TCG GTG TGAACG GAT TTG, reverse: TGTAGA CCA TGT AGT TGA GGT CA). GAPDH expression levels were used as reference for normalization.

\section{Statistical analysis}

Statistical analyses were done using SPSS11.5 software. Statistical analysis of adhesion scores was performed using Kruskal-Wallis test with pairwise Mann-Whitney $U$ tests in each region: anterior, middle and posterior. The values were presented in the box plot style. All other results of quantitative real time PCR and signal intensity of activated SFK were evaluated by one-way analysis of variance (ANOVA) to compare the differences of means among multi-group data followed by a Tukey-Kramer's post hoc test. $p<0.05$ was considered to represent significant differences between control and experimental groups.

\section{Acknowledgement}

Financial support was provided by National Institute of Dental and
Craniofacial Research Grant (RO1 DE16296) and CPF Cleft/Craniofacial Etiology Research Grant 2013 to CS.

\section{References}

AIKAWA, R., NAGAI, T., KUDOH, S., ZOU, Y., TANAKA, M., TAMURA, M., AKAZAWA, H., TAKANO, H., NAGAI, R. and KOMURO, I. (2002). Integrins play a critical role in mechanical stress-induced p38 MAPK activation. Hypertension 39: 233-238.

ARIAS-SALGADO, E.G., LIZANO, S., SARKAR, S., BRUGGE, J.S., GINSBERG, M.H. and SHATTIL, S.J. (2003). Src kinase activation by direct interaction with the integrin beta cytoplasmic domain. Proc Natl Acad Sci U S A 100: 13298-13302.

BAIN, J., PLATER, L., ELLIOTT, M., SHPIRO, N., HASTIE, C.J., MCLAUCHLAN, H., KLEVERNIC, I., ARTHUR, J.S., ALESSI, D.R. and COHEN, P. (2007). The selectivity of protein kinase inhibitors: a further update. Biochem $J$ 408: 297-315.

BUSH, J.O. and JIANG, R. (2012). Palatogenesis: morphogenetic and molecular mechanisms of secondary palate development. Development 139: 231-243.

CALAUTTI, E., CABODI, S., STEIN, P.L., HATZFELD, M., KEDERSHA, N. and PAOLO DOTTO, G. (1998). Tyrosine phosphorylation and src family kinases control keratinocyte cell-cell adhesion. J Cell Biol 141: 1449-1465.

CALAUTTI, E., GROSSI, M., MAMMUCARI, C., AOYAMA, Y., PIRRO, M., ONO, Y., $\mathrm{LI}, \mathrm{J}$. and DOTTO, G.P. (2002). Fyn tyrosine kinase is a downstream mediator of Rho/PRK2 function in keratinocyte cell-cell adhesion. J Cell Biol 156: 137-148.

FREBOURG, T., OLIVEIRA, C., HOCHAIN, P., KARAM, R., MANOUVRIER, S., GRAZIADIO, C., VEKEMANS, M., HARTMANN, A., BAERT-DESURMONT, S., ALEXANDRE, C. et al., (2006). Cleft lip/palate and CDH1/E-cadherin mutations in families with hereditary diffuse gastric cancer. J Med Genet 43: 138-142.

GALLIHER, A.J. and SCHIEMANN, W.P. (2006). Beta3 integrin and Src facilitate transforming growth factor-beta mediated induction of epithelial-mesenchymal transition in mammary epithelial cells. Breast Cancer Res 8: R42.

GALLIHER-BECKLEY, A.J. and SCHIEMANN, W.P. (2008). Grb2 binding to Tyr284 in TbetaR-II is essential for mammary tumor growth and metastasis stimulated by TGF-beta. Carcinogenesis 29: 244-251.

GATO, A., MARTINEZ, M.L., TUDELA, C., ALONSO, I., MORO, J.A., FORMOSO, M.A., FERGUSON, M.W. and MARTINEZ-ALVAREZ, C. (2002). TGF-beta(3)induced chondroitin sulphate proteoglycan mediates palatal shelf adhesion. Dev Biol 250: 393-405.

HAN, Q., LENG, J., BIAN, D., MAHANIVONG, C., CARPENTER, K.A., PAN, Z.K., HAN, J. and HUANG, S. (2002). Rac1-MKK3-p38-MAPKAPK2 pathway promotes urokinase plasminogen activator mRNA stability in invasive breast cancer cells. J Biol Chem 277: 48379-48385.

HUVENEERS, S. and DANEN, E.H. (2009). Adhesion signaling - crosstalk between integrins, Src and Rho. J Cell Sci 122: 1059-1069.

KAARTINEN, V., VONCKEN, J.W., SHULER, C., WARBURTON, D., BU, D., HEISTERKAMP, N. and GROFFEN, J. (1995). Abnormal lung development and cleft palate in mice lacking TGF-beta 3 indicates defects of epithelial-mesenchymal interaction. Nat Genet 11: 415-421.

KIM, Y., KUGLER, M.C., WEI, Y., KIM, K.K., LI, X., BRUMWELL, A.N. and CHAPMAN, H.A. (2009). Integrin alpha3beta1-dependent beta-catenin phosphorylation links epithelial Smad signaling to cell contacts. J Cell Biol 184: 309-322.

LIM, C.J., KAIN, K.H., TKACHENKO, E., GOLDFINGER, L.E., GUTIERREZ, E., ALLEN, M.D., GROISMAN, A., ZHANG, J. and GINSBERG, M.H. (2008). Integrinmediated protein kinase $\mathrm{A}$ activation at the leading edge of migrating cells. $\mathrm{Mol}$ Biol Cell 19: 4930-4941.

MALIK, R.K. and PARSONS, J.T. (1996). Integrin-dependent activation of the p70 ribosomal S6 kinase signaling pathway. J Biol Chem 271: 29785-29791.

MARTINEZ-SANZ, E., DEL RIO, A., BARRIO, C., MURILLO, J., MALDONADO, E., GARCILLAN, B., AMOROS, M., FUERTE, T., FERNANDEZ, A., TRINIDAD, E. et al., (2008). Alteration of medial-edge epithelium cell adhesion in two Tgf-beta3 null mouse strains. Differentiation 76: 417-430.

MCLACHLAN, R.W., KRAEMER, A., HELWANI, F.M., KOVACS, E.M. and YAP, A.S. (2007). E-cadherin adhesion activates c-Src signaling at cell-cell contacts. Mol Biol Cell 18: 3214-3223.

MUNGER, J.S. and SHEPPARD, D. (2011). Cross talk among TGF-beta signaling pathways, integrins, and the extracellular matrix. Cold Spring Harb Perspect Biol 3: a005017.

PATWARDHAN, P. and RESH, M.D. (2010). Myristoylation and membrane binding 
regulate C-Src stability and kinase activity. Mol Cell Biol 30: 4094-4107.

PECHKOVSKY, D.V., SCAFFIDI, A.K., HACKETT, T.L., BALLARD, J., SHAHEEN, F., THOMPSON, P.J., THANNICKAL, V.J. and KNIGHT, D.A. (2008). Transforming growth factor beta 1 induces alphavbeta 3 integrin expression in human lung fibroblasts via a beta3 integrin-, c-Src-, and p38 MAPK-dependent pathway. $J$ Biol Chem 283: 12898-12908.

SPANDIDOS, A., WANG, X., WANG, H. and SEED, B. PrimerBank: a resource of human and mouse $P C R$ primer pairs for gene expression detection and quantification. Nucleic Acids Res 38: D792-D799.

SUN, D., MCALMON, K.R., DAVIES, J.A., BERNFIELD, M. and HAY, E.D. (1998). Simultaneous loss of expression of syndecan-1 and E-cadherin in the embryonic palate during epithelial-mesenchymal transformation. Int J Dev Biol 42: 733-736.

THOMAS, S.M. and BRUGGE, J.S. (1997). Cellular functions regulated by Src family kinases. Annu Rev Cell Dev Biol 13: 513-609.
TSUKITA, S., OISHI, K., AKIYAMA, T., YAMANASHI, Y. and YAMAMOTO, T. (1991) Specific proto-oncogenic tyrosine kinases of src family are enriched in cell-tocell adherens junctions where the level of tyrosine phosphorylation is elevated. $J$ Cell Biol 113: 867-879.

VAN ROY, F. and BERX, G. (2008). The cell-cell adhesion molecule E-cadherin. Cell Mol Life Sci 65: 3756-3788.

WENDT, M.K. and SCHIEMANN, W.P. (2009). Therapeutic targeting of the focal adhesion complex prevents oncogenic TGF-beta signaling and metastasis. Breast Cancer Res 11: R68.

WHITTARD, J.D. and AKIYAMA, S.K. (2001). Positive regulation of cell-cell and cellsubstrate adhesion by protein kinase A. J Cell Sci 114: 3265-3272.

XU, X., HAN, J., ITO, Y., BRINGAS, P., JR., DENG, C. and CHAI, Y. (2008). Ectodermal Smad4 and p38 MAPK are functionally redundant in mediating TGF-beta/BMP signaling during tooth and palate development. Dev Cell 15: 322-329. 


\section{Further Related Reading, published previously in the Int. J. Dev. Biol.}

TGF-beta3 is required for the adhesion and intercalation of medial edge epithelial cells during palate fusion

Consuelo Tudela, Miguel-Angel Formoso, Tamara Martínez, Raquel Pérez, Marta Aparicio, Carmen Maestro, Aurora Del Río, Elena Martínez, Mark Ferguson and Concepción Martínez-Alvarez

Int. J. Dev. Biol. (2002) 46: 333-336

Gene expression analysis reveals that formation of the mouse anterior secondary palate involves recruitment of cells from the posterior side

Qun Li and Jixiang Ding

Int. J. Dev. Biol. (2007) 51: 167-172

http://www.intjdevbiol.com/web/paper/062212ql

The TGF-beta type III receptor is localized to the medial edge epithelium during palatal fusion

X M Cui and C F Shuler

Int. J. Dev. Biol. (2000) 44: 397-402

http://www.intjdevbiol.com/web/paper/10949049

Bulging medial edge epithelial cells and palatal fusion

C Martínez-Alvarez, R Bonelli, C Tudela, A Gato, J Mena, S O’Kane and M W Ferguson Int. J. Dev. Biol. (2000) 44: 331-335

http://www.intjdevbiol.com/web/paper/10853831

Immunohistochemical localization of TGF-beta type II receptor and TGF-beta3 during palatogenesis in vivo and in vitro

$X$ M Cui, D Warburton, J Zhao, D L Crowe and C F Shuler

Int. J. Dev. Biol. (1998) 42: 817-820

http://www.intjdevbiol.com/web/paper/9727838

5 yr ISI Impact Factor $(2011)=2.959$

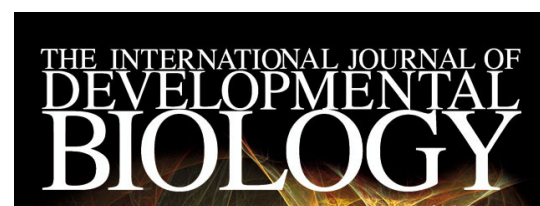

Volume 50 Nos. 2/3 1 Sinedial Issue

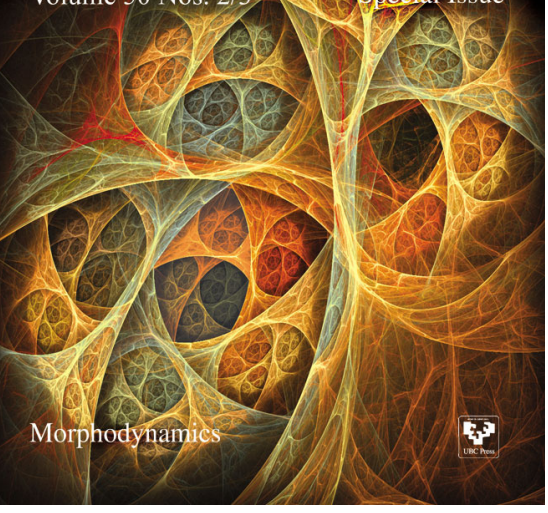

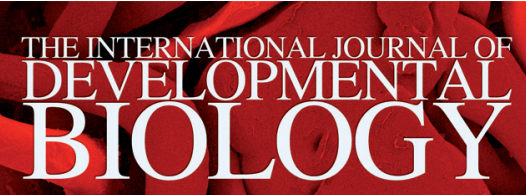

Volume 57 Nos. 2/3/4

Special Issue

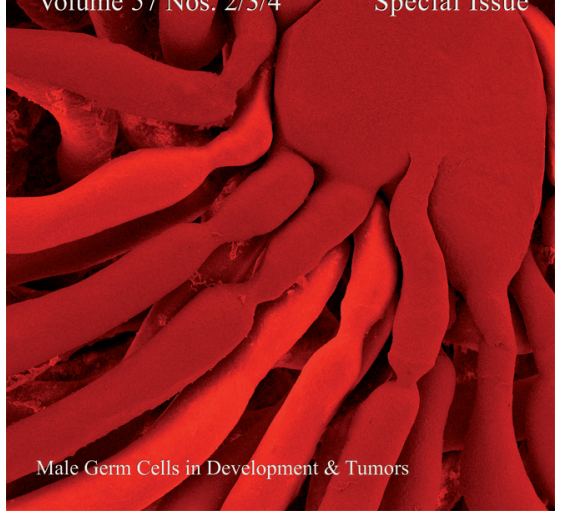

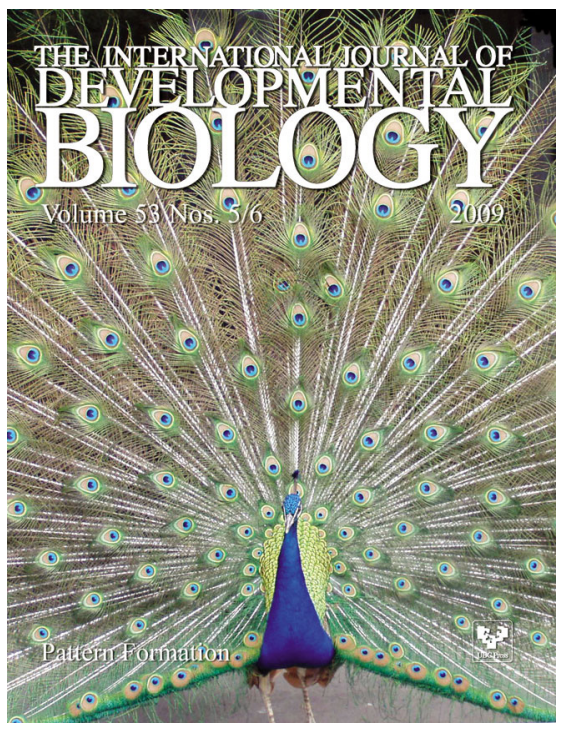

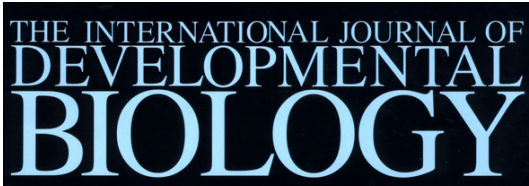

Volume 41 No. 2

April 1997

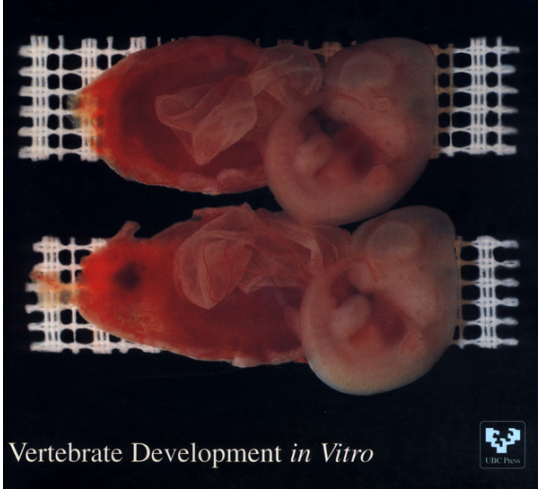

